\title{
OPTIMISED SEARCH HEURISTICS: A MAPPING OF PROCEDURES AND COMBINATORIAL OPTIMISATION PROBLEMS
}

\author{
Susana Fernandes \\ Universidade do Algarve, Faro, Portugal \\ sfer@ualg.pt \\ Helena R. Lourenço \\ Universitat Pompeu Fabra, Barcelona, Spain \\ helena.ramalhinho@econ.upf.es
}

\begin{abstract}
Recently hybrid metaheuristics have been design to find solutions for combinatorial optimisation problems. We focus on hybrid procedures that combine local search based metaheuristics with exact algorithms of the operations research field. We present a mapping that outlines the metaheuristic and exact procedures used, the way they are related and the problems they have been applied to.
\end{abstract}

\section{Introduction}

Recently a new type of algorithms, called hybrid metaheuristics, has been design to find solutions for combinatorial optimisation problems. Under the name of hybrid metaheuristics there are a huge variety of different types of procedures. They vary according to the algorithms combined, the level of hybridisation, the order of execution, the control strategy adopted, etc...(Raidl 2006). See the surveys of (Blum et al. 2005), (Cotta 1998), (Cotta et al. 2005), (Dumitrescu et al. 2003), (El-Abd et al. 2005), (Puchinger et al. 2005) and (Talbi 2002) for overviews of different angles.

In this research we are particularly interested in hybrid procedures that combine local search based metaheuristics with exact algorithms of the operations research field. We name them Optimised Search Heuristics (OSH). We present how this kind of procedures has been applied to combinatorial optimisation problems. We start by comparing and examining the correspondences of two existent classifications of such procedures and transform the more general one adding a new item and renaming other. To stress the distribution of these applications over the different problems of combinatorial optimisation, we then group the problems following a classification of NP optimisation problems, and outline the heuristic and exact techniques used together. We also present a very brief abstract of each referenced paper, outlining problems, procedures and type of combination used. 


\section{Classifications of $\mathrm{OSH}$ procedures}

Let us first present the two classifications of Optimised Search Heuristics.

\subsection{Classification of methods that combine local search with exact algorithms (Dumitrescu et al. 2003)}

Main framework by local search, sub problems by exact algorithms.

1 exact algorithms to explore large neighbourhoods within local search.

2 information of high quality solutions found in several runs of local search is used to define smaller problems solvable by exact algorithms.

3 exploit lower bounds in constructive heuristics.

4 local search guided by information from integer programming relaxations.

5 use exact algorithms for specific procedures within metaheuristics.

\subsection{Classification of exact and metaheuristics combinations (Puchinger et} al. 2005)

1 Collaborative

Algorithms exchange information but are not part of each other.

\subsection{Sequential execution}

One technique does a preprocessing before the other or the second one is a post processing of the solution(s) generated by the first. Sometimes both techniques have equal importance and we cannot speak of pre or post processing.

1.2 Parallel or intertwined execution

Several processors perform simultaneous tasks acting as teams and interchanging information.

2 Integrative combinations

One technique is a subordinate embedded component of the other technique

\subsection{Incorporating exact algorithms in metaheuristics}

\subsection{1 exactly solving relaxed problems}

Solutions to relaxations heuristically guide neighbourhood search, recombination, mutation, repair and/or local improvement.

\subsection{2 exactly searching large neighbourhoods}

Exact algorithms are used to search neighbourhoods in local search based metaheuristics.

\subsection{3 merging solutions}

Exact algorithms are used to solve sub problems generating partial solutions. Merging these partial solutions is iteratively applied within a metaheuristics.

\subsection{4 exact algorithms as decoders}

In evolutionary algorithms where solutions are incompletely represented in the chromosome, exact algorithms are used to find the correspondent best solution.

2.2 Incorporating metaheuristics in exact algorithms 
2.2.1 metaheuristics for obtaining incumbent solutions and bounds

Metaheuristics are used to determine bounds and incumbent solutions.

2.2.2 metaheuristics for column and cut generation

In branch-and-cut and branch-and-price algorithms, metaheuristics are used to dynamically separate cutting-planes and pricing columns, respectively.

\subsection{3 metaheuristics for strategic guidance of exact algorithms}

Metaheuristics are used to determine the branching strategy in branch-and-bound techniques.

2.2.4 applying the spirit of metaheuristics

Branch-and-bound it self is used for doing the local search. No explicit metaheuristic is used.

\section{Connecting the classification of Dumitrescu and Stützle with the one of Puchinger and Raidl}

Almost all items in the classification of Dumitrescu et al. correspond to sub items of item 2.1 (incorporating exact algorithms in metaheuristics), of the classification of Puchinger et al.. The exceptions are procedures classified by Dumitrescu and Stützle in item 2. (information of high quality solutions found in several runs of local search is used to define smaller problems solvable by exact algorithms), that have a sequential nature, running a local search based heuristic several times before an exact algorithm; and also the work of (Umetani et al. 2003), allocated to item 4 of Dumitrescu et al., that sequentially executes tabu search after solving the integer programming relaxation.

Some works included in item 1 of the classification of Dumitrescu et al., exactly searching large neighbourhoods, can be viewed as a merging solutions kind of procedure.

We introduce a new item in the classification of Puchinger and Raidl, 2.1.5 exact algorithms for strategic guidance of metaheuristics. Here we include all works of item 3 of the classification of Dumitrescu and Stützle.

We believe item 2.1.3. merging solutions should be generalized and renamed exactly solving sub problems.

We can say that the classification of Dumitrescu and Stützle is more specific and the one of Puchinger and Raidl is more general.

\begin{tabular}{|c|c|}
\hline \multicolumn{2}{|c|}{ Correspondence between classifications } \\
\hline $\begin{array}{c}\text { Classification of Dumitrescu and } \\
\text { Stützle }\end{array}$ & Classification of Puchinger and Raidl \\
\hline $\begin{array}{l}\text { 1. exact algorithms to explore large } \\
\text { neighbourhoods within local search }\end{array}$ & $\begin{array}{l}\text { 2.1.2. exactly searching large neighbourhoods } \\
\text { 2.1.3. merging solutions - exactly solving sub } \\
\text { problems }\end{array}$ \\
\hline $\begin{array}{l}\text { 2. information of high quality solutions found in } \\
\text { several runs of local search is used to define } \\
\text { smaller problems solvable by exact algorithms }\end{array}$ & 1.1. sequential execution \\
\hline $\begin{array}{l}\text { 3. exploit lower bounds in constructive } \\
\text { heuristics. }\end{array}$ & $\begin{array}{l}\text { new item 2.1.5. exact algorithms for strategic } \\
\text { guidance of metaheuristics }\end{array}$ \\
\hline $\begin{array}{l}\text { 4. local search guided by information from } \\
\text { integer programming relaxations }\end{array}$ & 1.1. sequential execution \\
\hline $\begin{array}{l}\text { 5. use exact algorithms for specific procedures } \\
\text { within metaheuristics }\end{array}$ & 2.1.3. merging solutions \\
\hline
\end{tabular}




\section{Classes of some NP optimisation problems}

Using the classification of NP optimisation problems in http://www.nada.kth.se/ viggo/problemlist/, we have found OSH algorithms in the following categories.

\begin{tabular}{|c|c|c|c|}
\hline \multirow[t]{6}{*}{ Graph Theory } & \multirow{4}{*}{$\begin{array}{l}\text { Covering and } \\
\text { Partitioning }\end{array}$} & Graph colouring & $\begin{array}{l}\text { (Marino et al. 1999) } \\
\text { (Filho et al 2000) }\end{array}$ \\
\hline & & Frequency assignment & (Maniezzo et al. 2000) \\
\hline & & Linear arrangement & (Yagiura et al. 1996) \\
\hline & & Partitioning & $\begin{array}{l}\text { (Ahuja et al. 2000) } \\
\text { (Ahuja et al. 2002) }\end{array}$ \\
\hline & \multirow{2}{*}{$\begin{array}{l}\text { Subgraphs and } \\
\text { Supergraphs }\end{array}$} & Maximum Clique & (Balas et al. 1998) \\
\hline & & $\begin{array}{l}\text { Maximum Independent } \\
\text { Set }\end{array}$ & (Aggarwal et al. 1997) \\
\hline \multirow[t]{6}{*}{ Network Design } & Flow problems & & $\begin{array}{l}\text { (Büdenbender et al. } \\
2000) \\
\text { (Danna et al. 2005) }\end{array}$ \\
\hline & Location problems & p-median & $\begin{array}{l}\text { (Rosing et al. 1997) } \\
\text { (Rosing et al. 1998) } \\
\text { (Rosing 2000) } \\
\text { (Della-Croce et al. 2004) }\end{array}$ \\
\hline & \multirow[t]{3}{*}{ Routing problems } & Traveling salesman & $\begin{array}{l}\text { (Applegate et al. 1998) } \\
\text { (Applegate et al. 1999) } \\
\text { (Cook et al. 2003) } \\
\text { (Talukdar et al. 1998) } \\
\text { (Burke et al. 2001) } \\
\text { (Congram 2000) } \\
\text { (Cowling et al. 2005) } \\
\text { (Pesant et al. 1996) } \\
\text { (Pesant et al. 1999) } \\
\text { (Voudouris et al. 1999) } \\
\text { (Yagiura et al. 1996) }\end{array}$ \\
\hline & & Vehicle routing & $\begin{array}{l}\text { (Ibaraki et al. 2001) } \\
\text { (Thompson et al. 1989) } \\
\text { (Thompson et al. 1993) } \\
\text { (Shaw 1998) } \\
\text { (Danna et al. 2005) }\end{array}$ \\
\hline & & Quadratic assignment & $\begin{array}{l}\text { (Mautor et al. 1997) } \\
\text { (Mautor et al. 2001) } \\
\text { (Mautor 2002) } \\
\text { (Maniezzo 1999) }\end{array}$ \\
\hline & Spanning trees & Steiner trees & (Klau et al. 2004) \\
\hline \multirow[t]{3}{*}{ Storage and Retrieval } & \multirow[t]{3}{*}{ Data storage } & Bin packing & $\begin{array}{l}\text { (Puchinger et al. 2004) } \\
\text { (Alvim et al. 2003) } \\
\text { (Puchinger 2006) }\end{array}$ \\
\hline & & Rectangle packing & $\begin{array}{l}\text { (Imahori et al. 2003) } \\
\text { (Dowsland et al. 2004) }\end{array}$ \\
\hline & & Cutting stock & $\begin{array}{l}\text { (Bennell et al. 2001) } \\
\text { (Umetani et al. 2003) }\end{array}$ \\
\hline \multirow[t]{5}{*}{$\begin{array}{l}\text { Sequencing and } \\
\text { Scheduling }\end{array}$} & One processor & $\begin{array}{l}\text { One machine } \\
\text { scheduling }\end{array}$ & $\begin{array}{l}\text { (Congram et al. 2002) } \\
\text { (Lourenço et al. 2002) } \\
\text { (Yagiura et al. 1996) }\end{array}$ \\
\hline & Multi processor & $\begin{array}{l}\text { Parallel machine } \\
\text { scheduling }\end{array}$ & $\begin{array}{l}\text { (Clements et al. 1997) } \\
\text { (Ghirardi et al. 2005) }\end{array}$ \\
\hline & \multirow[t]{2}{*}{ Shop scheduling } & Flow shop scheduling & $\begin{array}{l}\text { (Nagar et al. 1995) } \\
\text { (Della-Croce et al. 2004) }\end{array}$ \\
\hline & & Job shop scheduling & $\begin{array}{l}\text { (Chen et al. 1993) } \\
\text { (Denzinger et al. 1999) } \\
\text { (Tamura et al. 1994) } \\
\text { (Adams et al. 1988) } \\
\text { (Applegate et al. 1991) } \\
\text { (Balas et al. 1998) } \\
\text { (Caseau et al. 1995) } \\
\text { (Lourenço 1995) } \\
\text { (Lourenço et al. 1996) } \\
\text { (Schaal et al. 1999) } \\
\text { (Danna et al. 2005) }\end{array}$ \\
\hline & Lot-sizing & & $\begin{array}{l}\text { (Staggemeier et al. 2002) } \\
\text { (Ozdamar et al. 2000) }\end{array}$ \\
\hline
\end{tabular}




\begin{tabular}{|c|c|c|c|}
\hline \multirow[t]{3}{*}{$\begin{array}{l}\text { Mathematical } \\
\text { Programming }\end{array}$} & Knapsack & $\begin{array}{l}\text { Multidimensional } \\
\text { knapsack }\end{array}$ & $\begin{array}{l}\text { (Plateau et al. 2002) } \\
\text { (Vasquez et al. 2001) } \\
\text { (Chu et al. 1998) } \\
\text { (Raidl 1998) } \\
\text { (Puchinger 2006) }\end{array}$ \\
\hline & $\begin{array}{l}\text { Generalized } \\
\text { assignment }\end{array}$ & & $\begin{array}{l}\text { (Feltl et al. 2004) } \\
\text { (Pigatti et al. 2005) }\end{array}$ \\
\hline & $\begin{array}{l}\text { Mixed Integer } \\
\text { Programming }\end{array}$ & & $\begin{array}{l}\text { (Pedroso 2004) } \\
\text { (French et al. 2001) } \\
\text { (Kostikas et al. 2004) } \\
\text { (Danna et al. 2005) } \\
\text { (Fischetti et al. 2003) }\end{array}$ \\
\hline \multirow[t]{3}{*}{ Others } & $\begin{array}{l}\text { Generalized Schwefel } \\
\text { Function }\end{array}$ & & (Cotta et al. 2003) \\
\hline & $\begin{array}{l}\text { Markov Decision } \\
\text { Processes }\end{array}$ & & (Lin et al. 2004) \\
\hline & $\begin{array}{l}\text { Optimization of } \\
\text { continuous problems }\end{array}$ & & (Hedar et al. 2004) \\
\hline
\end{tabular}

\section{Mapping the referenced works}

We now map the found papers into a table of combination type versus problem type, indicating in each cell, along with the reference of the work, the metaheuristics and exact algorithms used.

We can see that a lot of the research of procedures that combine metaheuristics with exact algorithms has been dedicated to the job shop scheduling problem and to routing problems. Packing problems and the multiple constraint knapsack problem have also received some considerable attention, as well as the more general class of mixed integer programming problems. We believe this can be viewed as a measurement of the earned reputation that these problems have of being the most difficult among the class of the NP complete problems. Practitioners are still not satisfied with the results achieved by traditional applications from stand-alone fields of knowledge.

When looking at the type of combination implemented, we see that the most popular are sequential execution, exactly searching large neighbourhoods (and here dynamic programming is the most used exact algorithm) and exactly solving subproblems. Genetic algorithms have been the metaheuristics procedures more frequently used in combination with exact algoritms, maybe because of it's low performance on their one.

The most common exact algorithms in this $\mathrm{OSH}$ procedures are, aside from dymanic programming, linear relaxations and branch-and-bound.

We believe using exact algorithms for strategic guidance of metaheuristics to be a very promising line of research. This away we can profit from the fast search of the space of solutions of the metaheuristics without getting lost in a "wandering" path, because of the guidance given by the exact algorithms. We find that another very interesting idea is the one of "applying the spirit of metaheuristics" when designing exact algorithms. 


\begin{tabular}{|c|c|c|c|c|c|c|c|c|c|c|c|}
\hline & $\begin{array}{l}1.1 \\
\text { Sequential } \\
\text { execution }\end{array}$ & $\begin{array}{l}1.2 \\
\text { Parallel or } \\
\text { intertwined } \\
\text { execution }\end{array}$ & $\begin{array}{l}2.1 .1 \\
\text { Exactly } \\
\text { solving } \\
\text { relaxed } \\
\text { problems }\end{array}$ & $\begin{array}{l}2.1 .2 \\
\text { Exactly } \\
\text { searching large } \\
\text { neighbourhoods }\end{array}$ & $\begin{array}{l}2.1 .3 \\
\text { Exactly } \\
\text { solving sub } \\
\text { problems }\end{array}$ & $\begin{array}{l}2.1 .4 \\
\text { Exact } \\
\text { algorithms } \\
\text { as decoders }\end{array}$ & $\begin{array}{l}2.1 .5 \\
\text { Exact } \\
\text { algorithms for } \\
\text { strategic } \\
\text { guidance of } \\
\text { metaheuristics }\end{array}$ & $\begin{array}{l}2.2 .1 \\
\text { Metaheuristics } \\
\text { for obtaining } \\
\text { incumbent } \\
\text { solutions and } \\
\text { bounds }\end{array}$ & $\begin{array}{l}2.2 .2 \\
\text { Metaheuristics } \\
\text { for column } \\
\text { and cut } \\
\text { generation }\end{array}$ & $\begin{array}{l}2.2 .3 \\
\text { Metaheuristics } \\
\text { for strategic } \\
\text { guidance of } \\
\text { exact } \\
\text { algorithms }\end{array}$ & $\begin{array}{l}2.2 .4 \\
\text { Applying the } \\
\text { spirit of } \\
\text { metaheuristics }\end{array}$ \\
\hline $\begin{array}{l}\text { Mixed } \\
\text { Integer }\end{array}$ & $\begin{array}{l}\text { (Pedroso } \\
\text { 2004) } \\
\text { LS, LR }\end{array}$ & & & & $\begin{array}{l}\text { (Pedroso } \\
\text { 2004) } \\
\text { TS, BB }\end{array}$ & & & & & $\begin{array}{l}\text { (French et al. } \\
2001) \\
\text { BB, GA } \\
\text { (Kostikas et al. } \\
\text { 2004) } \\
\text { BB, GP }\end{array}$ & $\begin{array}{l}\text { (Danna et al. } \\
\text { 2005) } \\
\text { BC, LS } \\
\text { (Fischetti et al. } \\
\text { 2003) } \\
\text { BB, LS }\end{array}$ \\
\hline $\begin{array}{l}\text { Graph } \\
\text { Colouring }\end{array}$ & & & & & $\begin{array}{l}\text { (Marino et al. } \\
\text { 1999) } \\
\text { GA, LP }\end{array}$ & & & & $\begin{array}{l}\text { (Filho et al. } \\
2000) \\
\text { CG, GA }\end{array}$ & & \\
\hline $\begin{array}{l}\text { Frequency } \\
\text { Assignment }\end{array}$ & & & & & & & $\begin{array}{l}\text { (Maniezzo et al. } \\
2000) \\
\text { ACO, LR, D, } \\
\text { BB }\end{array}$ & & & & \\
\hline Partitioning & & & & $\begin{array}{l}\text { (Ahuja et al. } \\
\text { 2000) LS, DP } \\
\text { (Ahuja et al. } \\
\text { 2002) LS, DP }\end{array}$ & $\begin{array}{l}\text { (Yagiura et al. } \\
\text { 1996) } \\
\text { GA, DP }\end{array}$ & & & & & & \\
\hline $\begin{array}{l}\text { Maximum } \\
\text { Independent } \\
\text { Set }\end{array}$ & & & & & $\begin{array}{l}\text { (Aggarwal et } \\
\text { al. 1997) } \\
\text { GA, IP }\end{array}$ & & & & & & \\
\hline $\begin{array}{l}\text { Maximum } \\
\text { Clique }\end{array}$ & & & & & $\begin{array}{l}\text { (Balas et al. } \\
\text { 1998) } \\
\text { GA, IP }\end{array}$ & & & & & & \\
\hline $\begin{array}{l}\text { Network } \\
\text { Design }\end{array}$ & & & & & $\begin{array}{l}\text { (Büdenbender } \\
\text { et al. 2000) } \\
\text { LS, IP }\end{array}$ & & & & & & $\begin{array}{l}\text { (Danna et al. } \\
\text { 2005) } \\
\text { BC, LS }\end{array}$ \\
\hline p-Median & $\begin{array}{l}\text { (Rosing et } \\
\text { al. 1997) } \\
\text { (Rosing et } \\
\text { al. 1998) } \\
\text { (Rosing } \\
\text { 2000) } \\
\text { LS, BB }\end{array}$ & & & & & & & & & $\begin{array}{l}\text { (Della-Croce et } \\
\text { al. 2004) } \\
\text { BS }\end{array}$ & \\
\hline $\begin{array}{l}\text { Quadratic } \\
\text { Assignment }\end{array}$ & & & & & $\begin{array}{l}\text { (Mautor et al. } \\
\text { 1997) } \\
\text { (Mautor et al. } \\
\text { 2001) } \\
\text { (Mautor 2002) } \\
\text { LS, IP }\end{array}$ & & $\begin{array}{l}\text { (Maniezzo } \\
\text { 1999) } \\
\text { ACO, LR, D, } \\
\text { BB }\end{array}$ & & & & \\
\hline
\end{tabular}




\begin{tabular}{|c|c|c|c|c|c|c|c|c|c|c|c|}
\hline & $\begin{array}{l}1.1 \\
\text { Sequential } \\
\text { execution }\end{array}$ & $\begin{array}{l}1.2 \\
\text { Parallel or } \\
\text { intertwined } \\
\text { execution }\end{array}$ & $\begin{array}{l}2.1 .1 \\
\text { Exactly } \\
\text { solving } \\
\text { relaxed } \\
\text { problems }\end{array}$ & $\begin{array}{l}2.1 .2 \\
\text { Exactly } \\
\text { searching large } \\
\text { neighbourhoods }\end{array}$ & $\begin{array}{l}2.1 .3 \\
\text { Exactly } \\
\text { solving sub } \\
\text { problems }\end{array}$ & $\begin{array}{l}2.1 .4 \\
\text { Exact } \\
\text { algorithms } \\
\text { as decoders }\end{array}$ & $\begin{array}{l}2.1 .5 \\
\text { Exact } \\
\text { algorithms for } \\
\text { strategic } \\
\text { guidance of } \\
\text { metaheuristics }\end{array}$ & $\begin{array}{l}2.2 .1 \\
\text { Metaheuristics } \\
\text { for obtaining } \\
\text { incumbent } \\
\text { solutions and } \\
\text { bounds }\end{array}$ & $\begin{array}{l}2.2 .2 \\
\text { Metaheuristics } \\
\text { for column } \\
\text { and cut } \\
\text { generation }\end{array}$ & $\begin{array}{l}2.2 .3 \\
\text { Metaheuristics } \\
\text { for strategic } \\
\text { guidance of } \\
\text { exact } \\
\text { algorithms }\end{array}$ & $\begin{array}{l}2.2 .4 \\
\text { Applying the } \\
\text { spirit of } \\
\text { metaheuristics }\end{array}$ \\
\hline Steiner Tree & $\begin{array}{l}\text { (Klau et al. } \\
2004 \text { ) } \\
\text { MA, CP }\end{array}$ & & & $\begin{array}{l}\text { (Klau et al. 2004) } \\
\text { MA, CP }\end{array}$ & & & & & & & \\
\hline $\begin{array}{l}\text { Travelling } \\
\text { Salesman }\end{array}$ & $\begin{array}{l}\text { (Applegate } \\
\text { et al. 1999) } \\
\text { ILK, BC } \\
\text { (Cook et } \\
\text { al. 2003) } \\
\text { ILK, DP }\end{array}$ & $\begin{array}{l}\text { (Talukdar et } \\
\text { al. 1998) } \\
\text { GA, IP }\end{array}$ & & $\begin{array}{l}\text { (Cowling et al. } \\
\text { 2005) } \\
\text { ILS, DP } \\
\text { (Burke et al. } \\
\text { 2001) } \\
\text { LS, VNS, DP } \\
\text { (Pesant et al. } \\
\text { 1996) } \\
\text { (Pesant et al. } \\
\text { 1999) } \\
\text { LS, CP } \\
\text { (Congram 2000) } \\
\text { ILS, DP } \\
\text { (Voudouris et al. } \\
\text { 1999) GLS, DP } \\
\end{array}$ & $\begin{array}{l}\text { (Yagiura et al. } \\
\text { 1996) } \\
\text { GA, DP }\end{array}$ & & & & & & \\
\hline $\begin{array}{l}\text { Vehicle } \\
\text { Routing }\end{array}$ & $\begin{array}{l}\text { (Ibaraki et } \\
\text { al. 2001) } \\
\text { ILS, DP }\end{array}$ & & & $\begin{array}{l}\text { (Thompson et al. } \\
\text { 1989) } \\
\text { (Thompson et al. } \\
\text { 1993) } \\
\text { VNS, DP }\end{array}$ & $\begin{array}{l}\text { (Shaw 1998) } \\
\text { TS, BB }\end{array}$ & & & & & & $\begin{array}{l}\text { (Danna et al. } \\
\text { 2005) } \\
\text { BC, LS }\end{array}$ \\
\hline Packing & & & & & & $\begin{array}{l}\text { (Puchinger et } \\
\text { al. 2004) } \\
\text { GA, BB } \\
\text { (Imahori et al. } \\
\text { 2003) } \\
\text { ILS, DP }\end{array}$ & $\begin{array}{l}\text { (Dowsland et } \\
\text { al. 2004) } \\
\text { GA, BB }\end{array}$ & $\begin{array}{l}\text { (Alvim et al. } \\
\text { 2003) } \\
\text { D, TS }\end{array}$ & $\begin{array}{l}\text { (Puchinger et } \\
\text { al. 2004) } \\
\text { (Puchinger } \\
\text { 2006) } \\
\text { BP,GA }\end{array}$ & & \\
\hline $\begin{array}{l}\text { Cutting } \\
\text { Stock }\end{array}$ & $\begin{array}{l}\text { (Umetani } \\
\text { et al. 2003) } \\
\text { ILS, LR } \\
\text { (Bennell et } \\
\text { al. 2001) } \\
\text { TS, LP }\end{array}$ & & & & & & & & & & \\
\hline Lot-sizing & & & & & & $\begin{array}{l}\text { (Staggemeier } \\
\text { et al. 2002) } \\
\text { GA, LP }\end{array}$ & & $\begin{array}{l}\text { (Ozdamar et al. } \\
\text { 2000) } \\
\text { LgR, SA }\end{array}$ & & & \\
\hline
\end{tabular}




\begin{tabular}{|c|c|c|c|c|c|c|c|c|c|c|c|}
\hline & $\begin{array}{l}1.1 \\
\text { Sequential } \\
\text { execution }\end{array}$ & $\begin{array}{l}1.2 \\
\text { Parallel or } \\
\text { intertwined } \\
\text { execution }\end{array}$ & $\begin{array}{l}2.1 .1 \\
\text { Exactly } \\
\text { solving } \\
\text { relaxed } \\
\text { problems }\end{array}$ & $\begin{array}{l}2.1 .2 \\
\text { Exactly } \\
\text { searching large } \\
\text { neighbourhoods }\end{array}$ & $\begin{array}{l}2.1 .3 \\
\text { Exactly } \\
\text { solving sub } \\
\text { problems }\end{array}$ & $\begin{array}{l}2.1 .4 \\
\text { Exact } \\
\text { algorithms } \\
\text { as decoders }\end{array}$ & $\begin{array}{l}2.1 .5 \\
\text { Exact } \\
\text { algorithms for } \\
\text { strategic } \\
\text { guidance of } \\
\text { metaheuristics }\end{array}$ & $\begin{array}{l}2.2 .1 \\
\text { Metaheuristics } \\
\text { for obtaining } \\
\text { incumbent } \\
\text { solutions and } \\
\text { bounds }\end{array}$ & $\begin{array}{l}2.2 .2 \\
\text { Metaheuristics } \\
\text { for column } \\
\text { and cut } \\
\text { generation }\end{array}$ & $\begin{array}{l}2.2 .3 \\
\text { Metaheuristics } \\
\text { for strategic } \\
\text { guidance of } \\
\text { exact } \\
\text { algorithms }\end{array}$ & $\begin{array}{l}2.2 .4 \\
\text { Applying the } \\
\text { spirit of } \\
\text { metaheuristics }\end{array}$ \\
\hline $\begin{array}{l}\text { Flow-Shop } \\
\text { Scheduling }\end{array}$ & $\begin{array}{l}\text { (Nagar et } \\
\text { al. 1995) } \\
\text { BB, GA }\end{array}$ & & & & & & & & & $\begin{array}{l}\text { (Della-Croce et } \\
\text { al. 2004)] } \\
\text { BS }\end{array}$ & \\
\hline $\begin{array}{l}\text { Job-Shop } \\
\text { Scheduling }\end{array}$ & & $\begin{array}{l}\text { (Chen et al. } \\
\text { 1993) } \\
\text { GA, IP } \\
\text { (Denzinger } \\
\text { et al. 1999) } \\
\text { BB, GA }\end{array}$ & $\begin{array}{l}\text { (Tamura } \\
\text { et al. } \\
\text { 1994) } \\
\text { IP, GA, } \\
\text { LgR }\end{array}$ & & $\begin{array}{l}\text { (Caseau et al. } \\
\text { 1995) } \\
\text { LS, CrP } \\
\text { (Applegate et } \\
\text { al. 1991) } \\
\text { LS, BB } \\
\text { (Adams et al. } \\
\text { 1988) LS; BB } \\
\text { (Balas et al. } \\
\text { 1998) GLS, } \\
\text { BB }\end{array}$ & & $\begin{array}{l}\text { (Lourenço } \\
\text { 1995) } \\
\text { ILS, BB } \\
\text { (Lourenço et al. } \\
\text { 1996) } \\
\text { ILS, TS, BB }\end{array}$ & $\begin{array}{l}\text { (Schaal et al. } \\
\text { 1999) } \\
\text { IPM, C, GA, } \\
\text { SA }\end{array}$ & & & $\begin{array}{l}\text { (Danna et al. } \\
\text { 2005) } \\
\text { BC, LS }\end{array}$ \\
\hline $\begin{array}{l}\text { One } \\
\text { Machine } \\
\text { Scheduling }\end{array}$ & & & & $\begin{array}{l}\text { (Congram et al. } \\
\text { 2002) } \\
\text { ILS, DP } \\
\text { (Lourenço et al. } \\
\text { 2002) } \\
\text { ILS, DP }\end{array}$ & $\begin{array}{l}\text { (Yagiura et al. } \\
\text { 1996) } \\
\text { GA, DP }\end{array}$ & & & & & & \\
\hline $\begin{array}{l}\text { Parallel } \\
\text { Machine } \\
\text { Scheduling }\end{array}$ & $\begin{array}{l}\text { (Clements } \\
\text { et al. 1997) } \\
\text { LS, DW, } \\
\text { LR, BB }\end{array}$ & & & & & & & & & $\begin{array}{l}\text { (Ghirardi et al. } \\
\text { 2005) } \\
\text { BS }\end{array}$ & \\
\hline Knapsack & $\begin{array}{l}\text { (Vasquez } \\
\text { et al. 2001) } \\
\text { TS, LR } \\
\text { (Plateau et } \\
\text { al. 2002) } \\
\text { IPM, PR, } \\
\text { SS }\end{array}$ & & $\begin{array}{l}\text { (Chu et al. } \\
\text { 1998) } \\
\text { GA, LR, } \\
\text { SR } \\
\text { (Raidl } \\
\text { 1998) } \\
\text { GA, LR, D }\end{array}$ & & & & $\begin{array}{l}\text { (Puchinger } \\
\text { 2006) } \\
\text { VNS, LR }\end{array}$ & & & & \\
\hline $\begin{array}{l}\text { Generalized } \\
\text { Assignment }\end{array}$ & $\begin{array}{l}\text { (Feltl et al. } \\
\text { 2004) } \\
\text { GA, LP }\end{array}$ & & & & & & & & & & $\begin{array}{l}\text { (Pigatti et al. } \\
\text { 2005) } \\
\text { BCP, LS }\end{array}$ \\
\hline $\begin{array}{l}\text { Markov } \\
\text { Decision } \\
\text { Processes }\end{array}$ & $\begin{array}{l}\text { (Lin et al. } \\
\text { 2004) } \\
\text { GA, IP }\end{array}$ & & & & & & & & & & \\
\hline
\end{tabular}




\begin{tabular}{|c|c|c|c|c|c|c|c|c|c|c|c|}
\hline & $\begin{array}{l}1.1 \\
\text { Sequential } \\
\text { execution }\end{array}$ & $\begin{array}{l}1.2 \\
\text { Parallel or } \\
\text { intertwined } \\
\text { execution }\end{array}$ & $\begin{array}{l}2.1 .1 \\
\text { Exactly } \\
\text { solving } \\
\text { relaxed } \\
\text { problems }\end{array}$ & $\begin{array}{l}2.1 .2 \\
\text { Exactly } \\
\text { searching large } \\
\text { neighbourhoods }\end{array}$ & $\begin{array}{l}2.1 .3 \\
\text { Exactly } \\
\text { solving sub } \\
\text { problems }\end{array}$ & $\begin{array}{l}2.1 .4 \\
\text { Exact } \\
\text { algorithms } \\
\text { as decoders }\end{array}$ & $\begin{array}{l}2.1 .5 \\
\text { Exact } \\
\text { algorithms for } \\
\text { strategic } \\
\text { guidance of } \\
\text { metaheuristics }\end{array}$ & $\begin{array}{l}2.2 .1 \\
\text { Metaheuristics } \\
\text { for obtaining } \\
\text { incumbent } \\
\text { solutions and } \\
\text { bounds }\end{array}$ & $\begin{array}{l}2.2 .2 \\
\text { Metaheuristics } \\
\text { for column } \\
\text { and cut } \\
\text { generation }\end{array}$ & $\begin{array}{l}2.2 .3 \\
\text { Metaheuristics } \\
\text { for strategic } \\
\text { guidance of } \\
\text { exact } \\
\text { algorithms }\end{array}$ & $\begin{array}{l}2.2 .4 \\
\text { Applying the } \\
\text { spirit of } \\
\text { metaheuristics }\end{array}$ \\
\hline $\begin{array}{l}\text { Generalized } \\
\text { Schwefel } \\
\text { Function }\end{array}$ & & & & & $\begin{array}{l}\text { (Cotta et al. } \\
2003 \text { ) } \\
\text { GA, BB }\end{array}$ & & & & & & \\
\hline $\begin{array}{l}\text { Optimisation } \\
\text { of } \\
\text { continuous } \\
\text { problems }\end{array}$ & & & & & & & $\begin{array}{l}\text { (Hedar et al. } \\
\text { 2004) } \\
\text { TS, NM }\end{array}$ & & & & \\
\hline
\end{tabular}

\section{Heuristics}

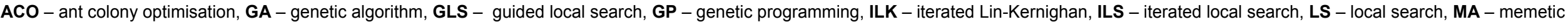
algorithm, PR - path relinking, SA - simulated annealing, SS - scatter search, TS - tabu search, VNS - variable neighbourhood search

Exact methods

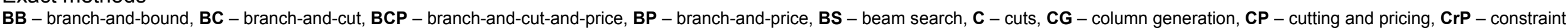
programming, D - duality, DP - dynamic programming, DW - Dantzing Wolf, IP - integer programming, IPM - interior point method, LP - linear programming, LgR - lagrangean relaxation, LR - linear relaxation, NM - Nelder-Mead method, SR - surrogate relaxation 


\section{Short abstracts of reference works}

\section{Sequential execution}

(Clements et al. 1997)

Local search is used to find initial pre-solutions for the multi-job, parallel machine scheduling problem, with lateness and changeover costs. The priority heuristic with local search schedules blocks of jobs in each line of production. The integer programming problem is a set partitioning, where groups of schedules have to be chosen. Dantzing-Wolf solves the linear relaxation of the IP and then branch-and-bound finds integer solutions.

(Pedroso 2004)

The procedure solves the linear relaxation of the mixed integer problem and sets the integer values by random enumeration. It ends with a local search.

(Ibaraki et al. 2001)

The procedure is applied to the vehicle routing problem. Iterated local search determines the number of routes and the order in it, dynamic programming optimizes the times of the routes.

(Umetani et al. 2003)

Initial solutions for the iterated local search are built by heuristics based on the linear relaxation solution of the one-dimensional cutting stock problem.

(Bennell et al. 2001)

The procedure is applied to the irregular stock cutting problem. Tabu search finds local optima of incomplete neighbourhoods. These solutions are improved by solving a linear program that uses the geometric concept of no fit polygon.

(Vasquez et al. 2001)

The procedure is applied to the multidimensional knapsack problem. Linear relaxation is solved with the extra constraint of the sum of the variables being an integer $\mathrm{k}$. Upper and lower limits for $\mathrm{k}$ are determined. Tabu search is executed for each one of the linear relaxation solutions sk. The neighbourhood is restricted to a small radius around sk.

(Klau et al. 2004)

This procedure is developed for the prize-collecting Steiner tree problem. A preprocessing phase reduces the graph. A memetic algorithm with problemdependent operators and an exact local search procedure is applied to the reduced graph. Solving the integer programming problem of a minimum Steiner arborescence optimises the solutions found by the memetic algorithm. When solving the integer problem, not all the complicating constraints are included in the model, only the violated by the current solution. Also not all variables are included, only the ones needed. So the procedure uses cutting and pricing. This is a very complicated algorithm.

(Nagar et al. 1995)

This procedure is applied to the 2-machine flow shop scheduling problem. In a first phase the algorithm executes an incomplete branch-and-bound, and the partial solutions are stored along with their respective bounds. The second 
phase is a genetic algorithm that uses the information of the bounds to decide upon the mutation operator.

(Feltl et al. 2004)

This procedure is defined for the generalized assignment problem and is based on the algorithm of Chu and Beasley (1996). Initial solutions for the genetic algorithm are generated by randomly rounding the linear relaxation solution. The mutation operator consists of a heuristic procedure that preserves feasibility.

(Lin et al. 2004)

This procedure is designed for the partially observed markov decision processes problem. The genetic algorithm generates an initial sub-set of witness points. A mixed integer program is solved to find the remaining ones.

(Plateau et al. 2002)

This procedure is applied to the multiconstrained knapsack problem. It starts by executing an interior point method with early termination. Feasible solutions are built by rounding and ascendant heuristics with will be the initial population for a scatter search method, with path-relinking.

(Applegate et al. 1999)

In a first phase of this procedure several tours for the traveling salesman problem are generated using an iterated Lin-Kernighan algorithm. The second phase uses a branch-and-cut algorithm to solve the problem defined over the subgraph with only the edges used by the tours found in the first phase.

(Cook et al. 2003)

In a first phase of this procedure several tours for the traveling salesman problem are generated using an iterated Lin-Kernighan algorithm. The second phase uses a dynamic programming algorithm to solve the problem defined over the subgraph with only the edges used by the tours found in the first phase.

(Rosing et al. 1997) (Rosing et al. 1998) (Rosing 2000)

This procedure is named heuristic concentration and is applied to the p-median problem. The first phase consists of doing multi random starts of a local search procedure and choose a set of the best solutions found. In the second phase a branch-and-bound method is used to solve a p-median problem, where the possible facility locations are restricted to the ones chosen in the best local search solutions.

\section{Parallel or intertwined execution}

(Chen et al. 1993)

This is an Asynchronous Teams (Talukdar et al. 2003) kind of procedure where some agents are genetic algorithms and others are techniques of integer programming. It is applied to the job shop scheduling problem.

(Talukdar et al. 1998) 
This is an Asynchronous Teams (Talukdar et al. 2003) procedure applied to the travelling salesman problem. Different agents are genetic algorithms and integer programming techniques.

(Denzinger et al. 1999)

This procedure is a parallelization of several agents, ones are branch-andbound and the others are genetic algorithms. It is designed for the job shop scheduling problem.

\section{Exactly solving relaxed problems}

(Chu et al. 1998)

This procedure is designed for the multiconstrained knapsack problem. Some elements of the population of the genetic algorithm are infeasible solutions generated by crossover and mutation operator. To recover feasibility of these solutions, the dual variables of the linear relaxation are used as weights in the surrogate relaxation of the multidimensional knapsack problem. A greedy heuristic based on the surrogate relaxation produces feasible solutions.

(Tamura et al. 1994)

This procedure is a genetic algorithm applied to the job-shop scheduling. The fitness of each individual, whose chromosomes represent each variable of the integer programming formulation, is the bound obtained solving lagrangian relaxations.

(Raidl 1998)

This procedure is designed for the multiconstrained knapsack problem. The initial population of the genetic algorithm is generated randomly setting the $0 / 1$ variables to one, with a probability given by its values on the linear relaxation solution. The repair operator to regain feasibility after crossover and mutation is also based on the solution values of the linear relaxation.

\section{Exactly searching large neighbourhoods}

(Congram et al. 2002)

Dynamic programming finds the best neighbour in a local search neighbourhood of exponential size. A perturbation is performed on the solution and dynasearch is iterated. The procedure is applied to the problem of scheduling a single machine with total weighted tardiness.

(Cowling et al. 2005)

The procedure is applied to the asymmetric travelling salesman problem. Local search uses a neighbourhood of 2 unconnected segments of the tour. Dynamic programming is used to optimally reconnect cities within the segments. The variable neighbourhood search version uses several k-opt neighbourhoods.

(Klau et al. 2004)

This procedure is developed for the prize-collecting Steiner tree problem. A preprocessing phase reduces the graph. A memetic algorithm with problemdependent operators and an exact local search procedure is applied to the reduced graph. Solving the integer programming problem of a minimum Steiner 
arborescence optimises the solutions found by the memetic algorithm. When solving the integer problem, not all the complicating constraints are included in the model, only the violated by the current solution. Also not all variables are included, only the ones needed. So the procedure uses cutting and pricing. This is a very complicated algorithm.

(Thompson et al. 1989) (Thompson et al. 1993)

This procedure defines a local search procedure with a neighbourhood structure based on the cyclic transfer concept. The exponential sized neighbourhood is exactly explored defining appropriated auxiliary graphs and using dynamic programming. A variable depth search technique is employed. The procedure is applied to the vehicle routing problem.

(Congram 2000)

Dynamic programming finds the best neighbour in a local search neighbourhood of exponential size. A perturbation is performed on the solution and dynasearch is iterated. The procedure is applied to the travelling salesman problem.

(Burke et al. 2001)

This procedure is designed to the traveling salesman problem. The local search routine is based on splitting the original problem into small subproblems of connecting fixed subtours, which are solved to optimality by dynamic programming. The local search is embedded in a variable neighbourhood procedure.

(Lourenço et al. 2002)

A dynasearch is used as a local search routine inside an iterated local search procedure, applied to the single machine waited tardiness problem.

(Ahuja et al. 2000) (Ahuja et al. 2002)

Very large neighbourhoods are exactly searched by network flow techniques, dynamic programming or by polynomial time solvable restrictions of the original problem. An application to the minimum spanning tree problem is described.

(Voudouris 1997) (Voudouris et al. 1999)

Dynasearch is used as a local search routine within a guided local search procedure applied to the traveling salesman problem.

(Pesant et al. 1996) (Pesant et al. 1999)

This procedure is developed within a constraint programming framework and applied to the traveling salesman with time windows. Each neighbourhood exploration is performed by branch-and-bound, defining elaborate local search moves.

\section{Exactly solving subproblems}

\section{(Pedroso 2004)}

The procedure is applied to mixed integer programming problems. Tabu search sets the values of integer variables and then a linear program is solved. Tabu search uses branch-and-bound as an intensification strategy. 
(Cotta et al. 2003)

Branch-and-bound is used to optimally complete a partial solution build with the recombination operator of the genetic algorithm. This procedure is applied to the following problems: generalized schwefel function, rulebase learning in mobile agents, design of a brachystochrone, k-epistatic minimal permutation.

(Marino et al. 1999)

The crossover of the genetic algorithm uses the optimal solution of the linear assignment formulation for the maximal sub-graph with zero clashes of the graph coloring problem.

(Mautor et al. 1997) (Mautor et al. 2001) (Mautor 2002) The MIMAUSA algorithm is designed to the quadratic assignment problem. The local search neighbourhood is defined deleting the value of some $k$ variables. The correspondent subproblem of assigning values to those variables is exactly solved by integer programming.

(Büdenbender et al. 2000)

This procedure is built for the network design problem. Each neighbouring solution of the local search is generated fixing the value of some variables and leaving the others free. The subproblem defined on the free subset of variables is solved to optimality by integer programming techniques.

(Caseau et al. 1995)

The local search procedure is applied to the job shop scheduling problem. The neighbourhood structure is defined by a subproblem that is exactly solve using constraint programming.

(Shaw 1998)

This tabu search procedure is designed for a vehicle routing problem. Branchand-bound is used to exactly explore a partial neighbourhood structure, defined by a subproblem.

(Applegate et al. 1991)

The local search type shuffle heuristic was built for the job shop scheduling problem. At each step the processing orders of the jobs on a small number of machines is fixed, and a branch-and-bound algorithm completes the schedule.

(Yagiura et al. 1996)

This is a genetic algorithm for permutation problems. In the crossover operator, common chromosomes of two parent solutions are kept fixed and the free ones are optimised using dynamic programming.

(Aggarwal et al. 1997)

This is a genetic procedure designed to the maximum independent set problem. In the recombination phase, the union of the features of two parent solutions defines an integer programming subproblem, which is solved to optimality.

(Balas et al. 1998)

This is a genetic procedure designed to the maximum clique problem. In the crossover operator, a subproblem is defined by the union of the features of two parent solutions, which is then solved exactly by integer programming. 
(Adams et al. 1988)

The shifting bottleneck procedure is an iterated local search applied to the job shop scheduling problem, with a construction heuristic that uses a branch-andbound to solve the subproblems of one machine with release and due dates.

(Balas et al. 1998)

This is a guided local search, over a tree search structure, that reconstructs partially destroyed solutions for the job shop problem, using a branch-andbound algorithm to exactly solve one machine subproblems

\section{Exact algorithms as decoders}

(Staggemeier et al. 2002)

The procedure is applied to the lot-sizing problem. The genetic algorithm schedules products and linear programming optimises sizes of lots for a given schedule, determining the fitness value of each element of the population. A heuristic of the asymmetric tsp type is used within the genetic algorithm to reoptimise all changes produced by crossover or mutation.

(Puchinger et al. 2004)

The individuals of the genetic algorithms are coded solutions of the twodimensional bin-packing problem with scheduling. Branch-and-bound is used to decode coded solutions. This procedure is developed for a real cutting glass problem.

(Imahori et al. 2003)

Dynamic programming evaluates codified solutions found by local search by determining the optimal real solution that corresponds to the codified one. The codified solution is perturbed and local search is iterated. The procedure is applied to the rectangle packing problem.

\section{Exact algorithms for strategic guidance of metaheuristics}

(Hedar et al. 2004)

The procedure is developed for the optimisation of continuous problems. The neighbourhood of the tabu search is generated according to extreme directions using the Nelder-Mead method and the pattern search strategy. Tabu list is managed by anti-cycling rules.

(Dowsland et al. 2004)

The representation of the individuals in the genetic algorithm is related to the search tree, as each position in the string corresponds to the choice of the branch at that level. Each individual corresponds to a path from the top of the tree to a terminal node. This way bounds can be calculated to partial solutions, guiding crossover and mutation operators. This procedure is applied to the rectangle packing problem.

(Maniezzo 1999) (Maniezzo et al. 2000)

The procedure is an Ant Colony Optimisation metaheuristic that uses information from the linear relaxation and the values of the dual variables to determine the pheromones, which guide the construction of solutions. The 
procedure has been applied to problems like quadratic assignment (1999) and frequency assignment (2000).

(Lourenço 1995) (Lourenço et al. 1996)

The iterated local search procedure is applied to the job shop scheduling problem. In the perturbation phase, subproblems of one or two machines are solved by a branch-and-bound algorithm.

(Puchinger 2006)

This is a variable neighbourhood search algorithm for the multidimensional knapsack problem. The order in which the neighbourhood are investigated within the variable neighbourhood descent is dynamically determined by estimating their improvement potential using solutions of linear relaxations problems.

\section{Metaheuristics for obtaining incumbent solutions and bounds}

(Alvim et al. 2003)

The procedure is applied to the one-dimensional bin-packing problem. The related min-max problem is solved by greedy heuristics to find the number of bins. Upper and lower bounds are calculated using the algebraic structure of the problem. Solutions are determined solving the dual bin-packing problem heuristically. Tabu search transforms remaining infeasible solutions into feasible ones.

(Schaal et al. 1999)

Interior point method generates initial solutions of the linear relaxation. The genetic algorithm finds integer solutions. A cut is generated based on the integer solutions found and the interior point method is applied again to diversify the search. This procedure is defined for the generalized job shop problem.

(Ozdamar et al. 2000)

Subproblems of the multi-level, multi-item, capacitated lot-sizing problem are derived by lagrangean relaxation. Solutions of these subproblems update lower bounds and lagrangean multipliers. A recursive heuristic is applied to restore capacity feasibility of the subproblems solutions and then simulated annealing finds complete solutions, providing upper bounds. The procedure is repeated with the updated lagrangean multipliers.

(Woodruff 1999)

This is a branch-and -bound procedure that uses a chunking-based selection strategy to decide at each node of the tree whether or not a reactive tabu search is run to improve the incumbent solution.

\section{Metaheuristics for column and cut generation}

(Filho et al. 2000)

This procedure is applied to the graph colouring problem. The genetic algorithm is used, with a given number of columns, to approximately solve a weighted maximum independent set problem; witch generates the initial pool of columns needed for the column generation process. Each column forms an independent 
set. Column generation solves the set covering formulation. The all procedure is repeated with the number of columns minus one, until no improvement is found.

(Puchinger et al. 2004) (Puchinger 2006)

The genetic algorithm is used within the branch-and-price procedure to solve the column generation. This procedure is applied to the $2 \mathrm{D}$ bin-packing problem.

(Puchinger et al. 2004)

\section{Metaheuristics for strategic guidance of exact methods}

(French et al. 2001)

This procedure is used to solve feasibility and optimisation integer programming problems and is inspired on the algorithm of Beasley and Chu (1996). Bounds of the branch-and-bound tree are found relaxing integrality. The genetic algorithm builds integer solutions relaxing constraint satisfaction, using information from the tree nodes to generate chromosomes. The solutions found by the genetic algorithm determine the new nodes of the tree to be examined. The algorithm is exact and was incorporated in commercial software XPRESSMP.

(Kostikas et al. 2004)

The genetic programming is used for evolving the best branching heuristic to each instance. Genetic programming "trains" during a first phase of branch-andbound, finds the best branching heuristic and then branch-and-bound starts again with the learned strategy for branching. This procedure is applied to mix integer programming problems.

(Della-Croce et al. 2004)

Lagrangean relaxation is used to derive lower and upper bounds to the nodes of the limited branch-and-bound tree. The number of nodes per level is limited heuristically using valid and pseudo dominance conditions. The recovery step consists of performing a local search at the current node and determines the next node to be examined. This procedure is applied to the two machine flow shop scheduling and the uncapacitated p-median problems.

(Ghirardi et al. 2005)

The Beam Search procedure is applied to the scheduling problem with parallel machines. The neighbourhood of partial solutions is inspected by local search, recovering pruned solutions of a limited branch-and-bound tree.

\section{Applying the spirit of metaheuristics}

(Danna et al. 2005)

Within each node of a branch-and-cut tree, the solution of the linear relaxation is used to define the neighbourhood of the current best feasible solution. The local search consists in solving the restricted MIP problem defined by the neighbourhood. The procedure is applied to mixed integer problems like job shop, network design and multicommodity routing.

(Pigatti et al. 2005) 
This procedure is developed for the general assignment problem. Upper bounds for the nodes of the search tree are obtained solving a linear program that inspects a k-opt neighbourhood in polynomial time. Ellipsoidal cuts that define the neighbourhood are added to the linear problem. Ellipsoidal cuts are inspired in the path relinking idea.

(Fischetti et al. 2003)

This procedure, design to mixed integer problems, called local branching, is a branch-and-bound method with a branching strategy that determines the number of variables to remain unchanged, instead of specifying the specific variables to change. At each node of the branch-and-bound tree the commercial software Cplex is used to solve the sub MIP integer model. 


\section{REFERENCES}

1 Adams, J., E. Balas and D. Zawack (1988). "The Shifting Bottleneck Procedure for Job Shop Scheduling." Management Science, vol. 34(3): pp. 391-401.

2 Aggarwal, C. C., J. B. Orlin and R. P. Tai (1997). "An optimized crossover for the maximum independent set." Operations Research, vol. 45: pp. 226234.

3 Ahuja, R. K., O. Ergun, J. B. Orlin and A. P. Punnen (2002). "A survey of very large-scale neighborhood search techniques." Discrete Applied Mathematics, vol. 123(1-3): pp. 75-102.

4 Ahuja, R. K., J. B. Orlin and D. Sharma. (2000). "Very large-scale neighbourhood search." International Transactions in Operational Research: pp. 301-317.

5 Alvim, A. C. F., C. C. Ribeiro, F. Glover and D. J. Aloise (2003), "A hybrid improvement heuristic for the one-dimensional bin packing problem", Research Report, Catholic University Department of Computer Science.

6 Applegate, D., R. Bixby, V. Chvátal and W. Cook (1998). "On the solution of traveling salesman problems." Documenta Mathematica, Extra Volume ICM, vol. III: pp. 645-656.

7 Applegate, D., R. Bixby, V. Chvátal and W. Cook (1999), "Finding Tours in the TSP", Technical Report, 99885, Forschungsinstitut für Diskrete Mathematik, University of Bonn.

8 Applegate, D. and W. Cook (1991). "A Computational Study of the Job-Shop Scheduling Problem." ORSA Journal on Computing, vol. 3(2): pp. 149156.

9 Balas, E. and W. Niehaus (1998). "Optimized crossover-based genetic algorithms for the maximum cardinality and maximum weight clique problems." Journal of Heuristics, vol. 4(2): pp. 107-122.

10 Balas, E. and A. Vazacopoulos (1998). "Guided Local Search with Shifting Bottleneck for Job Shop Scheduling." Management Science, vol. 44(2): pp. 262-275.

11 Bennell, J. A. and K. A. Dowsland (2001). "Hybridizing Tabu Search with Optimization Techniques for Irregular Stock Cutting." Management Science, vol. 47(8): pp. 1160-1172.

12 Blum, C., A. Roli and E. Alba (2005). An introduction to metaheuristics techniques. In E. Alba ed. Parallel Metaheuristics, a New Class of Algorithms. pp. 3-42. John Wiley.

13 Büdenbender, K., T. Grünert and H.-J. Sebastian (2000). "A hybrid tabu search/branch-and-bound algorithm for the direct flight network design problem." Transportation Science, vol. 34(4): pp. 364-380.

14 Burke, E. K., P. I. Cowling and R. Keuthen (2001). Effective local and guided variable neighborhood search methods for the asymmetric travelling salesman problem. In E. Boers ed. Applications of Evolutionary Computing: EvoWorkshops 2001. vol 2037 of LNCS, pp. 203-212. Springer.

15 Caseau, Y. and F. Laburthe (1995), "Disjunctive scheduling with task intervals", Technical Report LIENS, 95-25, Ecole Normale Superieure Paris.

16 Chen, S., S. Talukdar and N. Sadeh (1993). "Job-shop-scheduling by a team of asynchronous agentes", Proceedings of the IJCAI-93 Workshop on Knowledge-Based Production, Scheduling and Control. Chambery France. 
17 Chu, P. C. and J. E. Beasley (1998). "A Genetic Algorithm for the Multidimensional Knapsack Problem." Journal of Heuristics, vol. 4: pp. 63-86.

18 Clements, D. P., J. M. Crawford, D. E. Joslin, G. L. Nemhauser, M. E. Puttlitz and M. W. P. Savelsbergh (1997). "Heuristic Optimization: A hybrid Al/OR approach", Proceedings of the Workshop on Industrial ConstraintDirected Scheduling.

19 Congram, R. K. (2000), "Polynomially Searchable Exponential Neighbourhoods for Sequencing Problems in Combinatorial Optimisation", PhD thesis, Faculty of Mathematical Studies, University of Southampton.

20 Congram, R. K., C. N. Potts and S. L. V. d. Velde (2002). "An Iterated Dynasearch Algorithm for the Single-Machine Total Weighted Tardiness Scheduling Problem." INFORMS Journal on Computing, vol. 14(1): pp. 52-67.

21 Cook, W. and P. Seymour (2003). "Tour merging via branch-decomposition." INFORMS Journal on Computing, vol. 15(3): pp. 233-248.

22 Cotta, C. (1998). "A study of hybridisation techniques and their application." IEEE Transactions on Evolutionary Computation, vol. 1(1): pp. 223-224.

23 Cotta, C., E. G. Talbi and E. Alba (2005). Parallel hybrid metaheuristics. In E. Alba ed. Parallel Metaheuristics, a New Class of Algorithms. pp. 347370. John Wiley.

24 Cotta, C. and J. M. Troya (2003). "Embedding Branch and Bound within Evolutionary Algorithms." Applied Intelligence, vol. 18: pp. 137-153.

25 Cowling, P. I. and R. Keuthen (2005). "Embedded local search approaches for routing optimization." Computers and Operations Research, vol. 32(3): pp. 465-490.

26 Danna, E., E. Rothberg and C. L. Pape (2005). "Exploring relaxation induced neighborhoods to improve MIP solutions." Mathematical Programming, Ser. A, vol. 102: pp. 71-90.

27 Della-Croce, F., M. Ghirardi and R. Tadei (2004). "Recovering Beam Search: Enhancing the Beam Search Approach for Combinatorial Optimization Problems." Journal of Heuristics, vol. 10: pp. 89-104.

28 Denzinger, J. and T. Offermann (1999). "On Cooperation between Evolutionary Algorithms and other Search Paradigms", Proceedings of the 1999 Congress on Evolutionary Computational.

29 Dowsland, K. A., E. A. Herbert, G. Kendall and E. Burke (2004). "Using tree bounds to enhance a genetic algorithm approach to two rectangle packing problems." European Journal of Operational Research.

30 Dumitrescu, I. and T. Stutzle (2003). Combinations of local search and exact algorithms. In G. R. Raidl ed. Applications of Evolutionary Computation. vol 2611 of LNCS, pp. 211-223. Springer.

$31 \mathrm{El}-\mathrm{Abd}, \mathrm{M}$. and M. Kamel (2005). "A taxonomy of cooperative search algorithms", In M. J. Blesa, C. Blum, A. Roli and M. Sampels eds., Proceedings of the Hybrid Metaheuristics:Second International Workshop, pp. 32-41. Springer.

32 Feltl, H. and G. R. Raidl (2004). "An Improved Hybrid Genetic Algorithm for the Generalized Assignment Problem", Proceedings of the ACM Symposium on Applied Computing.

33 Filho, G. R. and L. A. N. Lorena (2000). "Constructive Genetic Algorithm and Column Generation:an Application to Graph Coloring", Proceedings of the APORS'2000 - The fifth conference of the association of Asianpacific Operations Research Societies. 
34 Fischetti, M. and A. Lodi (2003). "Local Branching." Mathematical Programming Series B, vol. 98: pp. 23-47.

35 French, A. P., A. C. Robinson and J. M. Wilson (2001). "Using a Hybrid Genetic-Algorithm/Branch and Bound Approach to Solve Feasibility and Optimization Integer Programming Problems." Journal of Heuristics, vol. 7: pp. 551-564.

36 Ghirardi, M. and C. N. Potts (2005). "Makespan minimization on unrelated parallel machines: a Recovering Beam Search approach." European Journal of Operational Research, Special issue: Project Management and Scheduling, vol. 165(2): pp. 457-467.

37 Hedar, A.-R. and M. Fukushima (2004). "Tabu Search directed by direct local methods for nonlinear global optimization." Elsevier Science, vol. preprint.

38 Ibaraki, T., M. Kubo, T. Masuda, T. Uno and M. Yagiura (2001). "Effective Local search Algorithms for the Vehicle Routing Problem with General Time Window Constraints", Proceedings of the MiC' 2001.

39 Imahori, S., M. Yagiura and T. Ibaraki (2003). "Local search algorithms for the rectangle packing problem with general spatial costs." Mathematical Programming Ser. B, vol. 97: pp. 543-569.

40 Klau, G. W., I. Ljubíc, A. Moser, P. Mutzel, P. Neumer, U. Pferschy, G. Raidl and R. Weiskircher (2004). Combining a Memetic Algorithm with Integer Programming to Solve the Prize-Collecting Steiner Tree Problem. In K. Deb ed. Genetic and Evolutionary Computation - GECCO 2004. vol 3102 of LNCS, pp. 1304-1315. Springer-Verlag.

41 Kostikas, K. and C. Fragakis (2004). Genetic Programming for Guiding Branch and Bound Search. In M. K. e. al ed. Genetic Programming EuroGP 2004. vol 3003 of LNCS, pp. 113-124. Springer.

42 Lin, Z.-Z., J. C. Bean and C. C. White-III (2004). "A Hybrid Genetic/ Optimization Algorithm for Finite-Horizon, Partially Observed Markov Decision Processes." INFORMS Journal on Computing, vol. 16(1): pp. 27-38.

43 Lourenço, H. R. (1995). "Job-shop scheduling: Computational study of local search and large-step optimization methods." European Journal of Operational Research, vol. 83: pp. 347-367.

44 Lourenço, H. R., O. Martin and T. Stützle (2002). Iterated local search. In F. Glover and G. Kochenberger eds. Handbook of Metaheuristics, vol 57 of International Series in Operations Research \& Management Science, pp. 321-353. Kluwer Academic Publishers.

45 Lourenço, H. R. and M. Zwijnenburg (1996). Combining large-step optimization with tabu-search: Application to the job-shop scheduling problem. In I. H. Osman and J. P. Kelly eds. Meta-heuristics: Theory \& Applications. Kluwer Academic Publishers.

46 Maniezzo, V. (1999). "Exact and approximate nondeterministic tree-search procedures for the quadratic assignment problem." INFORMS Journal on Computing, vol. 11(4): pp. 358-369.

47 Maniezzo, V. and A. Carbonaro (2000). "An ANTS heuristic for the frequency assignment problem." Future Generation Computer Systems, vol. 16(8): pp. 927-935.

48 Marino, A., A. Prugel-Bennett and C. A. Grass (1999). "Improving graph coloring with linear programming and genetic algorithms", Proceedings of the EUROGEN 99, pp. 113-118. Jyvaskyia, Finland. 
49 Mautor, T. (2002). Intensification neighbourhoods for local search methods. In C. C. Ribeiro and P. Hansen eds. Essays and Surveys in Metaheuristics. pp. 493-508. Kluwer Academic Publishers.

50 Mautor, T. and P. Michelon (1997). "MIMAUSA: A new hybrid method combining exact solution and local search", Proceedings of the 2nd International Conference on Metaheuristics, p. 15. Sophia-Antipolis, France.

51 Mautor, T. and P. Michelon (2001), "MIMAUSA: an application of referent domain optimization", Technical Report, 260, Laboratoire d'Informatique, Universit'e d'Avignon et des Pays de Vaucluse.

52 Nagar, A., S. S. Heragu and J. Haddock (1995). "A meta-heuristic algorithm for a bi-criteria scheduling problem." Annals of Operations Research, vol. 63: pp. 397-414.

53 Ozdamar, L. and G. Barbarosoglu (2000). "An integrated Lagrangean relaxation-simulated annealing approach to the multi-level multi-item capacitated lot sizing problem." International Journal of Production Economics, vol. 68: pp. 319-331.

54 Pedroso, J. P. (2004), "Hybrid Enumeration Strategies for Mixed Integer Programming", Technical Report Series. DCC-2004-8.

55 Pedroso, J. P. (2004), "Tabu Search for Mixed Integer programming", Technical Report Series. DCC-2004-02.

56 Pesant, G. and M. Gendreau (1996). A view of local search in constraint programming. In E. Freuder ed. Proceedings of Constraint Programming 1996. vol 1118 of Lecture Notes in Computer Science, pp. 353-366. Springer Verlag.

57 Pesant, G. and M. Gendreau (1999). "A constraint programming framework for local search methods." Journal of Heuristics, vol. 5: pp. 255-279.

58 Pigatti, A., M. P. d. Aragão and E. Uchoa (2005). "Stabilized Branch-and-cutand-price for the Generalized Assignment Problem." Electronic Notes in Discrete Mathematics, vol. 19.

59 Plateau, A., D. Tachat and P. Tolla (2002). "A hybrid search combining interior point method and metaheuristics for 0-1 programming." International Transactions in Operational Research, vol. 9: pp. 731-746.

60 Puchinger, J. (2006), "Combining Metaheuristics and Integer Programming for Solving Cutting and Packing Problems", PhD thesis, Algorithms and Data Structures Group, Vienna University of Technology.

61 Puchinger, J. and G. R. Raidl (2004). An Evolutionary Algorithm for Column Generation in Integer Programming: an Effective Approach for 2D Bin Packing. In X. Y. e. al ed. Parallel Problem Solving from Nature - PPSN VIII. vol 3242 of LNCS, pp. 642-651. Springer.

62 Puchinger, J. and G. R. Raidl (2004), "Models and algorithms for three-stage two dimensional bin packing", Technical Report TR 186-1-04-04, Institute of Computer Graphics and Algorithms, Vienna University of Technology.

63 Puchinger, J. and G. R. Raidl (2005). "Combining Metaheuristics and Exact Algorithms in Combinatorial Optimization: A Survey and Classification." Lecture Notes in Computer Science, vol. 3562.

64 Puchinger, J., G. R. Raidl and G. Koller (2004). Solving a Real-World Glass Cutting Problem. In J. G. a. G. R. Raidl ed. Evolutionary Computation in Combinatorial Optimization - EvoCOP 2004. vol 3004 of LNCS, pp. 162173. Springer.

65 Raidl, G. R. (1998). "An improved genetic algorithm for the multiconstrained 0-1 knapsack problem", In D. B. Fogel ed., Proceedings of the 1998 
IEEE International Conference on Evolutionary Computation, pp. 207211. IEEE Press.

66 Raidl, G. R. (2006), "A Unified View on Hybrid Metaheuristics", Institute of Computer Graphics and Algorithms, Vienna University of Technology.

67 Rosing, K. E. (2000). "Heuristic concentration: a study of stage one." ENVIRON PLANN B, vol. 27(1): pp. 137-150.

68 Rosing, K. E. and C. S. ReVelle (1997). "Heuristic concentration: Two stage solution construction." European Journal of Operational Research: pp. 955-961.

69 Rosing, K. E. and C. S. ReVelle (1998). "Heuristic concentration and tabu search: A head to head comparison." European Journal of Operational Research, vol. 117(3): pp. 522-532.

70 Schaal, A., A. Fadil, H. M. Silti and P. Tolla (1999). "Meta heuristics diversification of generalized job shop scheduling based upon mathematical programming techniques", Proceedings of the Cp-ai-or'99.

71 Shaw, P. (1998), "Using constraint programming and local search methods to solve vehicle routing problems", Technical Report, ILOG S.A.

72 Staggemeier, A. T., A. R. Clark, U. Aickelin and J. Smith (2002). "A hybrid genetic algorithm to solve a lot-sizing and scheduling problem", Proceedings of the Conference of the International Federation of Operational Research Societies. Edinburgh, U.K.

73 Talbi, E. G. (2002). "A Taxonomy of Hybrid Metaheuristics." Journal of Heuristics, vol. 8: pp. 541-564.

74 Talukdar, S., L. Baeretzen, A. Gove and P. d. Souza (1998). "Asynchronous teams: Cooperation schemes for autonomous agents." Journal of Heuristics, vol. 4: pp. 295-321.

75 Talukdar, S., S. Murty and R. Akkiraju (2003). Asynchronous teams. In F. Glover and G. Kochenberger eds. Handbook of Metaheuristics. vol 57 of International Series in Operations Research \& Management Science, pp. 537-556. Kluwer Academic Publishers.

76 Tamura, H., A. Hirahara, I. Hatono and M. Umano (1994). "An approximate solution method for combinatorial optimisation." Transactions of the Society of Instrument and Control Engineers, vol. 130: pp. 329-336.

77 Thompson, P. and J. Orlin (1989), "The theory of cycle transfers", Technical Report OR-200-89, MIT Operations Research Center.

78 Thompson, P. and H. Psaraftis (1993). "Cycle transfer algorithm for multivehicle routing and scheduling problems." Operations Research, vol. 41: pp. 935-946.

79 Umetani, S., M. Yagiura and T. Ibaraki (2003). "One Dimensional Cutting Stock Problem to Minimize the Number of Different Patterns." European Journal of Operational Research, vol. 146: p. 146.

80 Vasquez, M. and J.-K. Hao (2001). "A Hybrid Approach for the 0-1 Multidimensional Knapsack problem", Proceedings of the International Joint Conference on Artificial Intelligence 2001, pp. 328-333.

81 Voudouris, C. (1997), "Guided Local Search for Combinatorial Optimization Problems", PhD thesis, Department of Computer Science, University of Essex.

82 Voudouris, C. and E. Tsang (1999). "Guided local search and its application to the traveling salesman problem." European Journal of Operational Research, vol. 113(2): pp. 469-499.

83 Woodruff, D. L. (1999). A chunking based selection strategy for integrating meta-heuristics with branch and bound. In S. V. e. al ed. Metaheuristics: 
Advances and Trends in Local Search Paradigms for Optimization. pp. 499-511. Kluwer Academic Publishers.

84 Yagiura, M. and T. Ibaraki (1996). "The use of dynamic programming in genetic algorithms for permutation problems." European Journal of Operational Research, vol. 92: pp. 387-401. 